This is an electronic reprint of the original article. This reprint may differ from the original in pagination and typographic detail.

\author{
Author(s): Viljanen, Anne; Mikkola, Tuija; Rantakokko, Merja; Kauppinen, Markku; Kaprio, \\ Jaakko; Rantanen, Taina
}

Title: $\quad$ Genetic effects on life-space mobility in older women

Year: $\quad 2013$

Version:

Please cite the original version:

Viljanen, A., Mikkola, T., Rantakokko, M., Kauppinen, M., Kaprio, J., \& Rantanen, T. (2013). Genetic effects on life-space mobility in older women. Journal of the American Geriatrics Society, 61(7), 1232-1234. https://doi.org/10.1111/jgs.12348

All material supplied via JYX is protected by copyright and other intellectual property rights, and duplication or sale of all or part of any of the repository collections is not permitted, except that material may be duplicated by you for your research use or educational purposes in electronic or print form. You must obtain permission for any other use. Electronic or print copies may not be offered, whether for sale or otherwise to anyone who is not an authorised user. 


\section{Genetic Effects on Life-Space Mobility in Older Women}

Anne Viljanen ${ }^{\text {a }}, \mathrm{PhD}$, Tuija M. Mikkola ${ }^{\mathrm{a}}, \mathrm{PhD}$, Merja Rantakokko ${ }^{\mathrm{a}}, \mathrm{PhD}$, Markku Kauppinen ${ }^{\text {a }}$, MSc, Jaakko Kaprio ${ }^{\text {b,c,d }}, \mathrm{PhD}, \mathrm{MD}$, and Taina Rantanen, $\mathrm{PhD}{ }^{\text {a }}$

\footnotetext{
a Gerontology Research Center and Department of Health Sciences, University of Jyväskylä, Jyväskylä, Finland

${ }^{\mathrm{b}}$ Department of Public Health, Hjelt Institute, University of Helsinki, Helsinki Finland ${ }^{\mathrm{c}}$ Institute of Molecular Medicine, University of Helsinki, Helsinki, Finland

${ }^{\mathrm{d}}$ Department of Mental Health and Substance Abuse Services, National Institute for Health and Welfare, Helsinki, Finland
}

\section{Corresponding author:}

Anne Viljanen

Gerontology Research Center

P.O Box 35 (Viveca)

FIN - 40014 University of Jyväskylä

Phone: $+358-40-8053603$

Fax: -

E-mail: anne.viljanen@jyu.fi

\section{Alternate corresponding author:}

Tuija Mikkola

Gerontology Research Center

P.O Box 35 (Viveca)

FIN - 40014 University of Jyväskylä

Phone: $+358-40-5025772$

Fax: -

E-mail: tuija.m.mikkola@jyu.fi

Funding sources: This study was funded by grants from the Academy of Finland. Jaakko Kaprio has been supported by the Academy of Finland Centre of Excellence in Complex Disease Genetics (grant numbers: 213506, 129680).

Abbreviated title: Genetic Effects on Life-space Mobility 


\section{LETTER TO THE EDITOR: RESEARCH}

To the Editor: The ability, safely and reliably, to go where, when and how a person wants to go is a fundamental part of active aging and one of the important considerations for research, practice and policy in the aging field. ${ }^{1}$ Life-space mobility describes persons' ability to move and travel in their living environment. It is based on the balance between internal physiologic capacity and the external challenges encountered in daily life. ${ }^{2,3}$ Restricted life-space mobility correlates with difficulties in basic and instrumental activities of daily living (ADL), difficulties in transportation, poorer physical and cognitive performance, depressive mood, and also with low income, female gender and older age. ${ }^{3,4,5}$ Previous studies on the factors underlying life-space mobility are scarce, and no previous study has attempted to estimate the relative contribution of genetic and non-genetic effects on life-space mobility.

This study forms part of the Finnish Twin Study on Aging (FITSA), launched in 2000 to study the contribution of genetic and environmental effects to the disablement process in older women ( $\mathrm{n}=434$ twin individuals from 217 pairs). The recruitment process has been described in more detail earlier. ${ }^{6}$ The data used in the present analyses are drawn from the third FITSA data collection round in 2011-12, when 91\% $(n=344)$ of the 377 surviving participants answered a structured, postal questionnaire. The Ethics Committee of the Central Finland Health Care District approved the study, and participants gave their informed consent.

Life-space mobility was measured with the University of Alabama at Birmingham Study of Aging Life-Space Assessment $(\mathrm{LSA})^{3}$, which was translated into Finnish as described earlier ${ }^{7}$. The life-space composite score reflects participants' mobility performance in daily 
life, comprising the distance, frequency, and level of independence of travel (range 0-120, higher score indicating better life-space mobility). ${ }^{3}$

Depressive symptomatology was measured using the Center for Epidemiologic Studies Depression Scale (CES-D) (range 0-60, higher score indicating more severe depressive symptoms). We treated the entire CES-D scale as missing if more than four of the twenty items were missing. ${ }^{8}$ We classified participants as having difficulties in basic ADL (eating, toileting, bathing, or dressing) or in instrumental ADL (using the telephone, managing money, preparing meals, shopping, doing light housework, or doing heavy housework) if she reported major difficulties in doing, or being unable to do, the task. Self-rated health, memory, vision, hearing, balance and fear of falling were assessed using either 3- or 5-point rating scales. Information on current living and driving status, as well as number of selfreported chronic diseases was also gathered.

We had full LSA data on both cotwins in 61 monozygotic (MZ) and 61 dizygotic (DZ) pairs, while in $28 \mathrm{MZ}$ and $44 \mathrm{DZ}$ pairs data from only one twin were available. $222(66 \%)$ participants reported unlimited life-space, meaning that they had travelled outside their town during the previous 4 weeks, and 158 (49\%) participants reported unlimited life-space even without any assistive devices or help from other persons. The life-space of 39 (12\%) participants was restricted to the immediate neighbourhood level. The mean life-space composite score was higher in MZ than DZ twins (64.2 vs. 55.0, p=.001) and the difference persisted when adjusted for age $(\mathrm{p}=.005)$. Furthermore, DZ twins were older, more often reported difficulties in walking $2 \mathrm{~km}$, and were less often active car drivers than MZ twins. (Table 1.) 
The intra class correlation for the life-space composite score was 0.430 within MZ twin pairs and 0.168 within DZ twin pairs. The age-adjusted, quantitative genetic modelling revealed that additive genetic effects accounted for $43 \%$ (95\% CI $21-61 \%$ ) of the total variance in the LSA score, with the remaining variance due to non-genetic effects, 57\% (95\% CI 39-79\%).

Genetic effects account for about two-fifths of individual differences in life-space mobility, while the remainder are accounted for by non-genetic effects. The observed genetic effects on life-space mobility may be explained by genetic effects on individual's competence i.e. internal physiologic capacity, such as postural balance ${ }^{9}$, walking speed and muscle strength ${ }^{10}$. The non-genetic effect on life-space mobility is likely to consist of the demands set for mobility by the living environment, and various lifestyle factors that have negative or positive influences on internal physiologic capacity. It is worth noting that genetic effects may also underlie the process of choosing one's living environment. Although genetic effects account for a marked proportion of life-space mobility, their relative importance can be attenuated by increasing environmental variability in terms of the living environment or living habits. Increase in physical activity, enhancement of the built environment, and transportation options will likely increase older persons' life-space and engagement in society. 


\section{ACKNOWLWEDGMENTS}

We are indebted to all the participants for their commitment to the study. The Gerontology Research Center is a joint effort between the University of Jyväskylä and the University of Tampere.

Conflict of interest: The authors have no financial or any other kind of personal conflicts with this paper.

Authors' contributions: Anne Viljanen: study concept and design, acquisition of data, analysis and interpretation of data, drafting the article, approval of manuscript. Tuija Mikkola, Merja Rantakokko and Markku Kauppinen: study concept and design, analysis and interpretation of data, critical revision of the article, approval of manuscript. Jaakko Kaprio and Taina Rantanen: study concept and design, acquisition of data, analysis and interpretation of data, critical revision of the article, approval of manuscript.

Sponsor's role: The sponsors did not have any role in the design, methods, subject recruitment, data collection, analysis, or preparation of this manuscript. 


\section{REFERENCES}

1. Satariano WA, Guralnik JM, Jackson RJ et al. Mobility and aging: New directions for public health action. Am J Public Health 2012;102:1508-1515.

2. Baker PS, Bodner EV, Allman RM. Measuring life-space mobility in community-dwelling older adults. J Am Geriatr Soc 2003;51:1610-1614.

3. Peel C, Baker PS, Roth DL et al. Assessing mobility in older adults: The UAB study of aging life-space assessment. Phys Ther 2005;85:1008-1019.

4. Shah RC, Maitra K, Barnes LL et al. Relation of driving status to incident life space constriction in community-dwelling older persons: A prospective cohort study. J Gerontol A Biol Sci Med Sci 2012;67:984-989.

5. Barnes LL, Wilson RS, Bienias JL et al. Correlates of life space in a volunteer cohort of older adults. Exp Aging Res 2007; 33:77-93.

6. Viljanen A, Kaprio J, Pyykko I et al. Hearing acuity as a predictor of walking difficulties in older women. J Am Geriatr Soc 2009;57:2282-2286

7. Rantanen T, Portegijs E, Viljanen A et al. Individual and environmental factors underlying life space of older people - study protocol and design of a cohort study on life-space mobility in old age (LISPE). BMC Public Health 2012; 12:1018.

8. Radloff LS. The CES-D scale: a self-report depression scale for research in the general population. Appl Psych Meas 1977;1:385-401.

9. Pajala S, Era P, Koskenvuo M et al. Contribution of genetic and environmental effects to postural balance in older female twins. J Appl Physiol 2004;96:308-315.

10. Tiainen KM, Perola M, Kovanen VM et al. Genetics of maximal walking speed and skeletal muscle characteristics in older women. Twin Res Hum Genet 2008;11:321-334 
Table 1. Characteristics of the Participants by Zygosity

\begin{tabular}{|c|c|c|c|c|c|c|}
\hline \multirow[b]{2}{*}{ Characteristic } & \multicolumn{2}{|c|}{ Monozygotic Twins } & \multicolumn{2}{|c|}{ Dizygotic Twins } & \multirow{2}{*}{$\begin{array}{l}\text { Wald } \\
\text { test } \\
\mathrm{p}\end{array}$} & \multirow{2}{*}{$\begin{array}{l}\text { Variance } \\
\text { ratio test } \\
\mathrm{p}\end{array}$} \\
\hline & $\mathrm{n}=11 \mathrm{C}$ & -162 & $n=144$ & -182 & & \\
\hline $\begin{array}{l}\text { Life-space composite score (range } 0 \text { - } 120 \text { ), } \\
\text { mean } \pm \text { SD }\end{array}$ & 64.2 & \pm 21.4 & 55.0 & \pm 21.6 & .001 & .910 \\
\hline Age, mean \pm SD & 78.6 & \pm 3.6 & 79.6 & \pm 3.0 & .034 & .017 \\
\hline CES-D score (range $0-60)$, mean \pm SD & 13.8 & \pm 8.0 & 14.4 & \pm 7.5 & .552 & .441 \\
\hline Number of chronic diseases, mean \pm SD & 3.6 & \pm 2.1 & 4.0 & \pm 2.4 & .268 & .078 \\
\hline \multicolumn{7}{|l|}{ Living status, $\mathrm{n}(\%)$} \\
\hline Alone in private accommodation & 79 & $(50.3)$ & 113 & $(62.4)$ & .107 & \\
\hline With someone in private accommodation & 74 & $(47.1)$ & 65 & $(35.9)$ & & \\
\hline In sheltered housing & 4 & $(2.5)$ & 3 & $(1.7)$ & & \\
\hline ADL difficulties, $\mathrm{n}(\%)$ & 14 & $(8.9)$ & 11 & $(6.2)$ & .349 & \\
\hline IADL difficulties, $\mathrm{n}(\%)$ & 51 & $(32.1)$ & 63 & $(35.0)$ & .598 & \\
\hline $500 \mathrm{~m}$ walking difficulties, $\mathrm{n}(\%)$ & 23 & $(14.2)$ & 32 & $(17.9)$ & .382 & \\
\hline $2 \mathrm{~km}$ walking difficulties, $\mathrm{n}(\%)$ & 40 & $(25.2)$ & 67 & $(37.6)$ & .024 & \\
\hline Active car driver, n (\%) & 45 & $(30.8)$ & 29 & $(18.1)$ & .025 & \\
\hline \multicolumn{7}{|l|}{ Self-rated health, n (\%) } \\
\hline Good or very good & 50 & $(31.6)$ & 41 & $(22.7)$ & .268 & \\
\hline Intermediate & 96 & $(60.8)$ & 125 & $(69.1)$ & & \\
\hline Poor or very poor & 12 & $(7.6)$ & 15 & $(8.3)$ & & \\
\hline \multicolumn{7}{|l|}{ Memory, n (\%) } \\
\hline Good or very good & 42 & $(26.6)$ & 55 & $(30.4)$ & .764 & \\
\hline Intermediate & 105 & $(66.5)$ & 114 & $(63.0)$ & & \\
\hline Poor or very poor & 11 & $(7.0)$ & 12 & $(6.6)$ & & \\
\hline \multicolumn{7}{|l|}{ Vision, $\mathrm{n}(\%)$} \\
\hline Good & 72 & $(45.9)$ & 81 & $(45.5)$ & .470 & \\
\hline Intermediate & 81 & $(51.6)$ & 88 & $(49.4)$ & & \\
\hline Poor & 4 & $(2.5)$ & 9 & $(5.1)$ & & \\
\hline \multicolumn{7}{|l|}{ Hearing, n (\%) } \\
\hline Good - no problems & 60 & $(37.3)$ & 92 & $(51.1)$ & & \\
\hline Slightly reduced & 91 & $(56.5)$ & 81 & $(45.0)$ & & \\
\hline Substantially reduced & 10 & $(6.2)$ & 7 & $(3.9)$ & .033 & \\
\hline \multicolumn{7}{|l|}{ Balance difficulties, n (\%) } \\
\hline Never & 84 & $(54.9)$ & 92 & $(52.0)$ & & \\
\hline Sometimes & 55 & $(35.9)$ & 66 & $(37.3)$ & .861 & \\
\hline Often or always & 14 & $(9.2)$ & 19 & $(10.7)$ & & \\
\hline \multicolumn{7}{|l|}{ Fear of falling, $\mathrm{n}(\%)$} \\
\hline Never & 45 & $(29.4)$ & 49 & $(27.4)$ & .676 & \\
\hline Sometimes & 87 & $(56.9)$ & 99 & $(55.3)$ & & \\
\hline Often or always & 21 & (13.7) & 31 & (17.3) & & \\
\hline
\end{tabular}

CES-D Center for Epidemiologic Studies Depression Scale

ADL Activities of daily living, IADL Instrumental activities of daily living

SD Standard deviation 